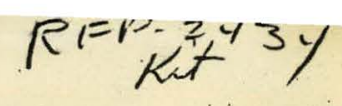

\title{
RADIATION MONITOR TRAINING PROGRAM AT ROCKY FLATS
}

\author{
$\therefore$ L. C. Medina, W. D. Kittinger, and R. M. Vogel
}

Health Sciences, Radiation Monitoring Department

Rockwell International, Atomics International Division Rocky Flats Plant; Golden, Colorado 80401

Energy Research and Development Administration

MASTER

(Contract No. E(29-2)-3533).

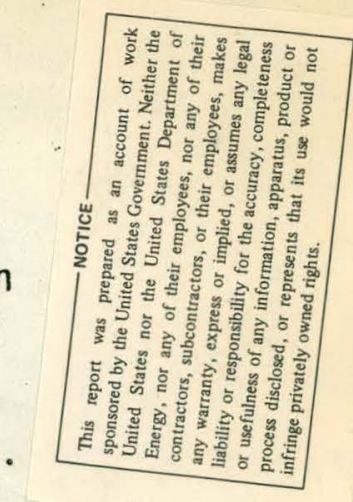

\section{Abstract}

The Rocky Flats Radiation Monitor Training Program is tailored to train new health physics personnel in the field of radiation monitoring. The purpose of the prescribed materials and media is to be cons.istent in training in all areas of Rocky flats radiation monitoring job involvement.

\section{Introduction}

Individuals who enter the Radiation Monitor classification at Rocky Flats, typically have no previous radiation work or health physics experience. Entering qualifications require high school completion or equivalency with course work in mathematics and physical science.

A proficiency in health physics monitoring knowledge and skills must be established through "in-house" training. Training is accomplished through a combination of on-the-job training, formal training, and experience, continuing over a four-year period.

A Radiation Monitor Progression Program is part of the Company-Union Labor agreement. The training specified herein conforms to and goes beyond the stipulations of that Program.

Training is conducted by Radiation Monittoring Supervision. Considerable on-the-job training instruction and assistance is given by more experienced radiation monitor co-workers.

The syllabus indicates major content, the timing, and methods of training. Unique requirements of the area to which the trainee is assigned will require changing emphasis in the content. The syllabus, however, indicates the general training intended to be accomplished.

\section{Training Criteria}

A monitor in training is assigned to day work for a period up to one year and is given on-the-job and formal classroom and related laboratory exercise training by his foreman and the Health sciences staff. The trainee is exposed to learning job techniques by working with experienced radiation monitors on various job assignments. 


\section{DISCLAIMER}

This report was prepared as an account of work sponsored by an agency of the United States Government. Neither the United States Government nor any agency Thereof, nor any of their employees, makes any warranty, express or implied, or assumes any legal liability or responsibility for the accuracy, completeness, or usefulness of any information, apparatus, product, or process disclosed, or represents that its use would not infringe privately owned rights. Reference herein to any specific commercial product, process, or service by trade name, trademark, manufacturer, or otherwise does not necessarily constitute or imply its endorsement, recommendation, or favoring by the United States Government or any agency thereof. The views and opinions of authors expressed herein do not necessarily state or reflect those of the United States Government or any agency thereof. 


\section{DISCLAIMER}

Portions of this document may be illegible in electronic image products. Images are produced from the best available original document. 
A documented supervisory evaluation is made on a daily basis for the first six weeks and a formal documented evaluation is given at the third and sixth month. If an evaluation. is unsatisfactory; the monitor's scheduled six-month wage increase is not granted and the trainee can be separated from the program.

At the end off six months; a written examination is given consisting of twenty questions selected from a panel of one hundred questions. Should the trainee fail the examination, he may elect to stay in the program in training status for an additional four weeks at which time he will again be examined. Any monitor in training who receives an unsatisfactory evaluation or fails the written examination a second time is separated from the Radiation Monitor program. and returned to-the-Employment department.

\section{Radiation Monitoring Training Program Outline}

TRAINING SEQUENCE

1. Orientation - First Week

2: Intensive Training - First Six Months

A. On-the-job. Training

B. Formal Training
a. Audio-Visual
b. Classroom - Laboratory Exercises

3. Work Experience - Six Months to Four Years

A. Building Area Assignment

4. Refresher Training - After Four Years

ORIENTATION - ONE WEEK

1. Orientation by Unit Leader

A. Organization Structure

B. Radiation Monitoring Function

a. Relationship To Other Groups

b. Importance of Job

C. Job Description

D. Overview of Training Program 
E. Issue of Materials
a. Study Manuals
b. Radiation Monitor Progression Program
c. Pocket Note Book
d. Radiation. Monitoring Training Workbook
e. Alpha Survey Instrument

2. Orientation by Foreman
A. How and Why of Monitoring operations
B. Tour Radiation Monitoring Areas
C. Tour Process Areas
D. Comment on Area. Tours
E. Teach Instrument Use
F. Overview of Material to be Taught
G. Safety
H. Review and Document First Week Orientation

INTENSIVE TRAINING - FIRST. TWENTY SIX WEEKS

1. On-the-job Training
A. Conducted and Evaluated by Supervision
B. Rotation of Area Assignment

2. Formal Self-Instructional Training - Ten Lessuils First 13. Weeks.
A. Audio-visual presentation.
B.. Evaluation of Workbook Results by Supervision
C. Unlimited Study Time 3. Classroom Training and Laboratory Expercises - 13th to
26 th Week
A. Conducted by Health Sciences Staff
B. Twelve Scheduled Classroom Hours 
Written Examination and Evaluation - 26 th Week WORK EXPERIENCE - Six Months through Four Years

1. Formal Documented Performance Evaluation - Every Six Months

2. Certificate Issued

REFRESHER TRAINING - After Four Years

1. Formal Training - As required to introduce new equipment, techniques and changing requirements.

2. Casual Training - Audio-Visual programs.

3. job Performance Evaluation - as needed.

Training Content

Present content of the training program in greater detail is as follows:

Monitor Trainee Orientation

This orientation is given during the new monitor's first week with Radiation Monitoring. The trainee is assigned to day shift during this period.

\section{Purpose}

The orientation is intended to instill in the new monitor, a feeling of self-confidence, a semse of belonging, and give an overview of the job and skills to be acquired.

\section{Techniques}

The appropriate Radiation Monitoring unit leader should begin the orientation. His orientation will consist of:

1. A discussion of organizational structure.

2. A description of purpose and functions of Radiation Monitoring and relationship to other groups. The importance of the job.

3. A description of the radiation monitor's job and relationship to other groups.

4. An overview of the training program and the supervisor's role in training.

5. Issue of job related materials and equipment.

6. Arrange for a meeting with Company and Union representatives of the Progression Program Committee. 
7. Schedule the new monitor to attend the Radiation Monitoring building indoctrination session.

The appropriate Radiation Monitoring foreman will conduct the remainder of the first week orientation. The foreman is expected to conduct the orientation along the following quidelines:

1. Introduce trainee to co-workers and office staff.

2. In the orientation, stress How and particularly Why elements of the monitors job are performed. Repeat points that have been covered. Ask questions of the trainee to ensure that instructions are understood.

3. Plan an orientation that combines visits through process areas to learn the areas, functions, and monitoring responsibilities in those areas with. later critique sessions in the training room.

4. Perform a daily evaluation for the trainee and record the information. Discuss the evaluation with the trainee. Use this session to guide emphasis in further training or to repeat training.

\section{Content}

1. Tour Radiation Monitoring area, discuss:

The facilities

Assignment board, builetin board, etc.

Elcictronics support group and facilities

Equipment storage

Counting equipment

Functions of staff

2. Tour process areas, discuss:

Monitor area assignments

Self-monitoring equipment

Emergency procedures and equipment

Monitor functions in an area with the monitor

assigned to the area. Let the experienced monitor

explain the duties and techniques.

3. Review area tours, discuss:

Items the trainee has learned

Items needing clarification

\section{REPETITION IS IMPORTANT}

4. Instruct the trainee in the use of the alpha survey instrument. Teach theory, allow practice, and correct mistakes. 
5. Present an overview of material taught.

6. Instruct regarding plant and department safety requirements.

Intensive Training

This phase of training occurs during the first twenty six weeks and culminates in a written examination and formal performance evaluation. The radiation monitor trainee must satisfactorily pass both examination and performance evaluations in order to continue in the training program.

\section{On-the-job Training}

- On the job training is conducted by the foreman with the assistance of experienced radiation monitors. Trainees are assigned to monitoring jobs. within the scope of train-. ing. Rotation of area assignments is employed whenever possible to broaden the experience base. Instrumentation, monitoring techniques, and responsibilities are emphasized.

Formal Self-Instructional Training

The foreman to whom the new monitor is assigned, conducts formal self-instructional sessions. Company time is alloted to study the material. The total time taken depends on the monitor!s needs. Audio-visual programs with workbooks are utilized to present the training material. .

The Audio-visual programs are as follows:

1. Basic Mathematics and Metric System.

(Further study in mathematics may ensue from determination of proficiency)

2. Introduction to Nuclear Physics (a three part program).

3. Radiation Instrumentation.

4. Respiratory Protection.

5. Records and Forms.

6. Supplied Air Operations.

7. Air Sampling.

8. Emergency Procedures.

9. Monitoring Techniques.

10. Final Review and Examination. 
Before proceeding with formal classroom sessions, it is required that all audio-visual programs be completed.

\section{Formal Classroom Sessions}

Formal classroom sessions are conducted on site, by Health Sciences. supervision and staff. Laboratory exercises and monitoring instrumentation are utilized to simulate job conditions and related problems.

At least twelve classroom hours are spent in formal training between the thirteenth through twenty-sixth week. Additional study time is also provided for the trainee in order that he might pursue deeper study of the classroom material. Supervision and staff members are available to answer questions and help solve problems the trainee might encounter.

The content in outline form is as follows:

A. : RADIATION STANDARDS

1. History

2. Derivation of Standards

3. Dosimetry Standards
a.. Internal
b. External

4. Definition of Terms

a. MPD, MPC, MPBB, etc.

5. Standards
a. ERDA
b. Plant

B. INSTRUMENTS - LABORATORY EXERCISE

1. Geomelry

2. Source Check

3. Statistics of Counting

4. Detailed Explanation
a. Ionizalion Chamber
b. Gas Proportional Counter 
c. Scintillation Counter

d. Geiger muller tube

5. Gereral Instrument Usage and Application

6. Isotopes

7. Inverse Square law

c. CALCULATIONS - LABORATORY EXERCISE

1. Sample Counting a. Air

1) Effluen't

2) Routine

3). Special

b. Geometry, Volume, Time

c. Unit Conversions

2. Industrial Hygiene. Sampling Techniques

D. SPECIAL MONITORING APPLICATIONS

1. Tritium Sampling Technique and Equipment

2. Site Survey Operations

3. Emergency support and Agreements
a. Internal (plant)
b. External

4. Radioactive or Contaminated Material Shipments
a. Internal (plant)
b. Externat
c. DOT, ERDA

E. VASTE CONTROL

1. Monitoring Techniques

2. Segregaliun, Packaging 
F. DISCUSSION OF PRINCIPAL ISOTOPES

1. Decay Chain

2. Principal Radiations

3. Metabolism

G. OPEN DISCUSSION AND REVIEW

H. HEALTH SCIENCES RELATED ACTIVITIES

1. Tour Building 123 Facilities

a. Body Counter

b. Dosimetry Lab

c. Sample counting and isotopic analys is

d. Electronics

2. Explanation and Briefing of Operations by Each Group

Refresher Training

Refresher training and updating in the technology is not currently a formalized program. All radiation monitors are requested to participate in taking the audio-visual lessons designed for new monitors. Seminars and information meetings are held as appropriate to disseminate technical information and procedural changes. 